\title{
Effect of monotonic lateral load on the performance of reinforced graded concrete column, an experimental study
}

\author{
M. Mirza Abdillah Pratama ${ }^{1, *}$, B. Sri Umniati ${ }^{1}$, Gista Prasiwi ${ }^{1}$, Ay Lie Han ${ }^{2}$, Buntara \\ Sthenly Gan $^{3}$, Puput Risdanareni ${ }^{1}$, and Zhabrinna Zhabrinna ${ }^{4}$ \\ ${ }^{1}$ Department of Civil Engineering, Faculty of Engineering, Universitas Negeri Malang, Indonesia \\ ${ }^{2}$ Department of Civil Engineering, Faculty of Engineering, Diponegoro University, Indonesia \\ ${ }^{3}$ Department of Architecture, College of Engineering, Nihon University, Koriyama, Japan \\ ${ }^{4}$ School of Engineering and Physical Science, University of Birmingham, The United Kingdom
}

\begin{abstract}
A gradation pattern in the strength of concrete columns is unavoidable due to the presence of static and dynamic segregation. The effect of concrete uniformity on columns subjected to monotonic lateral load is investigated experimentally in this study. Reinforced concrete columns with cross-sectional dimensions of $150 \times 150 \mathrm{~mm}$ and a height of $1000 \mathrm{~mm}$ are prepared as graded concrete column (GCC) specimens and controlling specimens. The columns are designed with a reinforcement ratio of $1 \%$. Two concrete mixes with a strength of $20 \mathrm{MPa}$ and $30 \mathrm{MPa}$ are cast in moulds using the gradual compaction procedure to create a satisfactory strength transition throughout the specimens' height. The resulting lateral deformation and resisting load are utilised for further analysis. The analyses show that the GCC exhibits a lower peak load and lateral deformation than the control specimen, and a distinct failure mode is observed. The GCC also shows more brittle behaviour in the post-peak region.
\end{abstract}

\section{Introduction}

Concrete is a composite material that is generally used for construction due to its ease of design and application of structural elements. Previous studies show that the height-towidth ratio of concrete elements affects the material's homogeneity because of the presence of segregation. In concrete technology, there are two types of segregation, namely dynamic segregation and static segregation. Dynamic segregation arises from the effects of compaction procedures that cause the coarse aggregate to gravitationally sink to the bottom part. On the other hand, static segregation happens immediately when concrete is cast. Static segregation is highly influenced by the dimension ratio of the elements and the characteristics of the concrete mix. The high use of a water-to-content ratio, for example, will result in a high fluidity of the concrete mix but a loss of viscosity

\footnotetext{
* Corresponding author: mirza.abdillah.ft@um.ac.id
} 
to hold the weight of the concrete constituent [1-3]. The segregation causes the element to create a graded structure which creates a material density concentration at the bottom and leaves a lower coarse aggregate-to-mortar ratio at the upper part of the element. As a result, a higher concrete strength is found at the bottom part and decreases as the elements' height increases [4-9]. In this research, the gradation in strength is created by combining two different concrete mix proportions in a column element. The specimen is designed to represent a critical section of RC columns by positioning the mix of lower concrete strength at the end-support where the maximum shear force exists. The column is then subjected to a monotonic lateral load; and the load carrying capacity, translation, and the failure modes are compared to the controlling specimen.

\section{Experimental programs}

\subsection{Design of RC columns}

A single specimen of RC columns with a graded structure is prepared along with the uniform RC column sized $150 \times 150 \times 1000 \mathrm{~mm}$. The column cross section is designed to possess a longitudinal reinforcing ratio equal to $1.17 \%$. The column features 4 (four) longitudinal bars with a diameter of $8 \mathrm{~mm}$ (undeformed). The rebars have satisfied the minimum reinforcing ratio provisioned by the Indonesian code as a non-composite compression member ranging from 1 to $8 \%$. The structure is predicted to undergo an under-reinforced failure mode, allowing the tension bars to yield before the failure of the concrete in compression fibre. The column height is considered to have a minimum height-to-width ratio of more than 3 (three). Details of the RC column and the reinforcing bars are presented in Fig. 1.
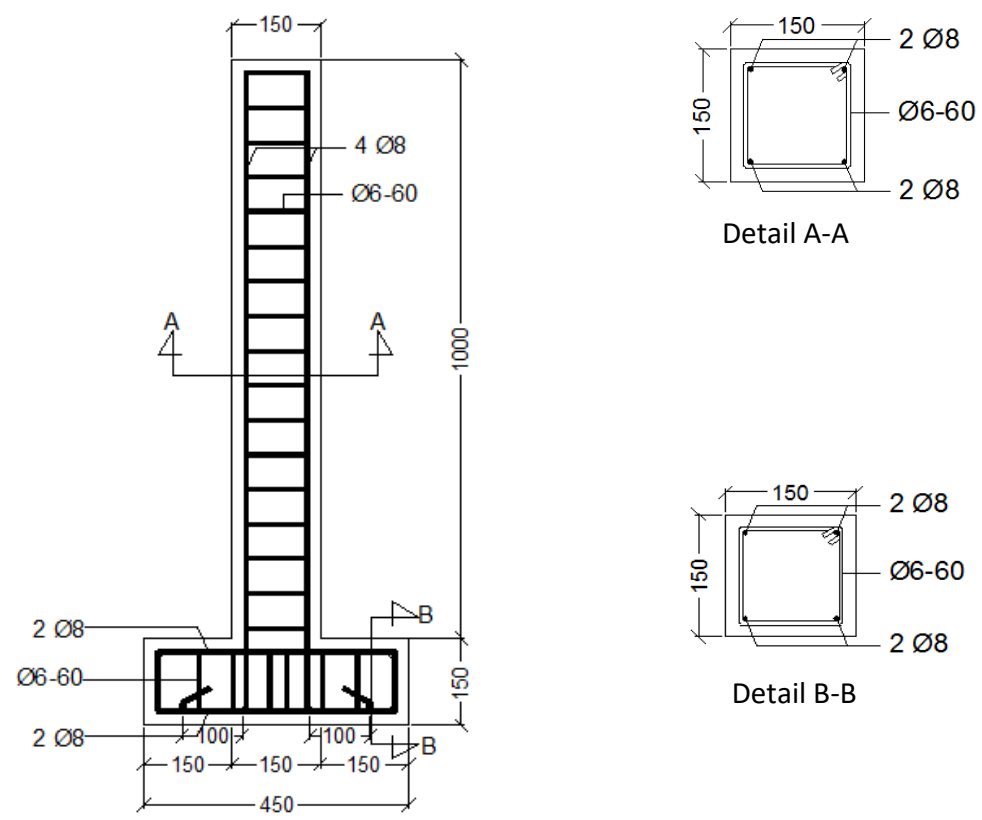

Detail B-B

Fig. 1. Detail of RC column. 
The graded concrete column (GCC) is designed by combining 2 (two) distinguished concrete strengths, which are $20 \mathrm{MPa}$ positioned at the bottom and $30 \mathrm{MPa}$ at the upper part. The concrete strength is adjusted to the strength that is generally used for housing. Fig. 2 (left) shows an RC column undergoing natural segregation that allows the mass of coarse aggregate to sink to the bottom and change the material homogeneity along the element's height. The placement of a lower concrete strength at the bottom part of the specimen is done to represent the upper section of the column possessing lower strength due to concrete segregation, and its susceptibility to a higher risk of shear force concentration (Fig. 2, right). The critical condition of the column modelling is presented in Fig. 2.

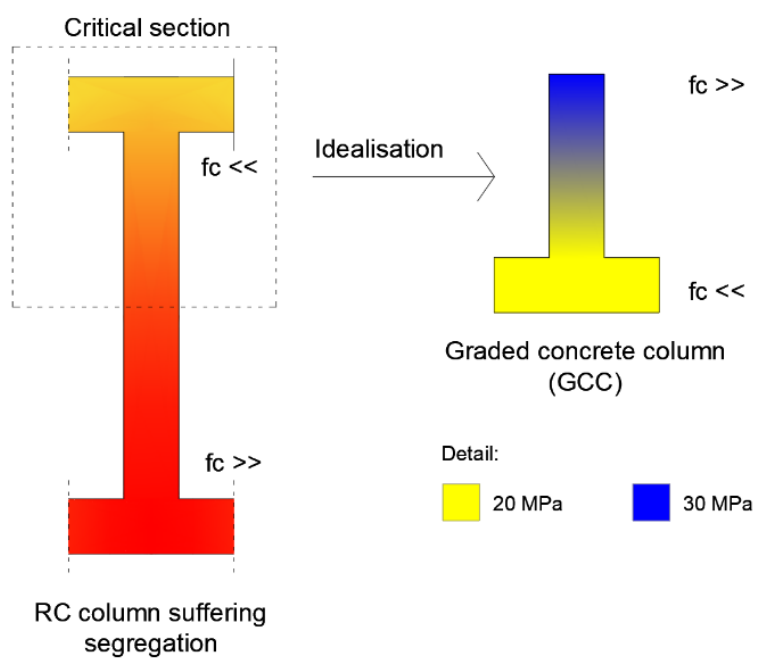

Fig. 2. Modelling of GCC.

\subsection{Concrete mix proportion}

The concrete mix proportion is designed in accordance with the procedure of the Department of Environment with a compressive strength equal to $20 \mathrm{MPa}$ and $30 \mathrm{MPa}$. All of the mixes are expected to produce a collapse slump ranging from 60 to $180 \mathrm{~mm}$. The mixing process is initially conducted by weighing concrete materials based on its proportions. Fresh concrete is prepared using a machine with the addition of superplasticiser to improve the workability. The concrete mixes are then cast in column frameworks and cylindrical moulds as control specimens. The concrete mix proportion in this study is recapped in Table 1.

Table 1. Concrete mix proportion.

\begin{tabular}{|c|c|c|c|c|c|}
\hline \multirow{2}{*}{$\begin{array}{c}\text { Concrete } \\
\text { strength } \\
(\mathrm{MPa})\end{array}$} & \multicolumn{5}{|c|}{ Ratio to cement weight } \\
\cline { 2 - 6 } & Cement & Water & Fine aggregate & $\begin{array}{c}\text { Coarse } \\
\text { aggregate }\end{array}$ & Superplasticiser \\
\hline 20 & 1.00 & 0.61 & 2.44 & 2.00 & 0.006 \\
\hline 30 & 1.00 & 0.50 & 1.94 & 1.59 & 0.006 \\
\hline
\end{tabular}




\subsection{Specimen making and curing}

Before the concrete placement, strain gauges are patched at the end stirrups where the shear force concentrates and at the tension longitudinal steel. The casting of the NC is begun by placing $20 \mathrm{MPa}$ mix at the stiffener section and compacted using a shaft vibrator. The cast is continued by pouring the concrete mix upwards until it finished. For GCC specimen, the concrete casting is initiated by pouring $20 \mathrm{MPa}$ mix at the bottom part of the column until half of the column height. A sequential compaction is applied using a concrete vibrator along with concrete casting. The $30 \mathrm{MPa}$ mix is then cast for $250 \mathrm{~mm}$ thick and compacted until the shaft vibrator reaches $250 \mathrm{~mm}$ above the base. The casting is completed by pouring the $30 \mathrm{MPa}$ mix until finished. This sequential compaction is intended to create a solid transition in concrete strength along the column's height. The casting scheme of the GCC is illustrated in Figure 3.

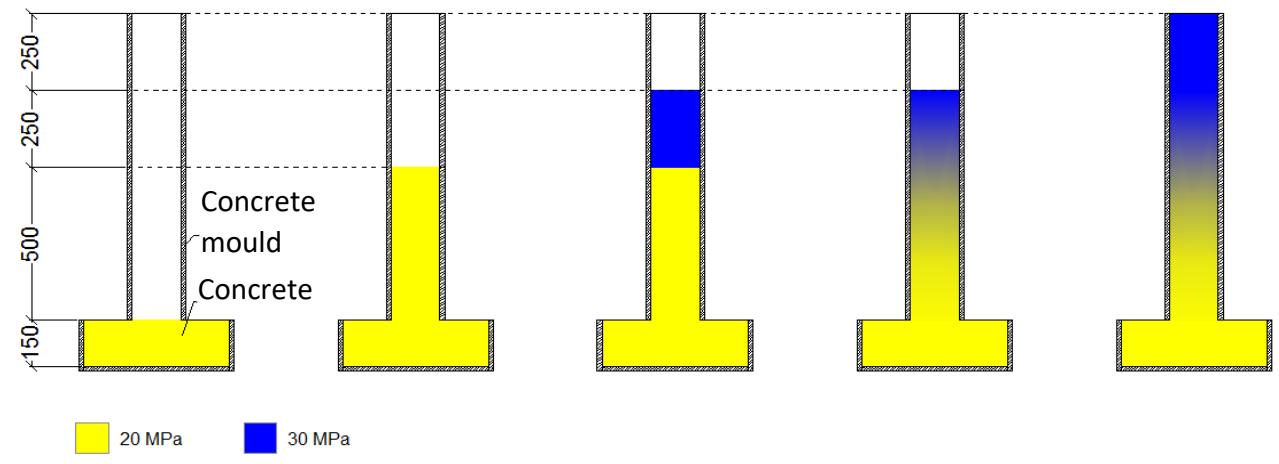

Fig. 3. Casting scheme of the graded concrete column.

The columns are de-moulded 24 hours after concreting and are continued with dry curing. Both the uniform RC column and GCC are covered using a wet towel to retain moisture for 20 days. At the last 7 (seven) days before testing, the columns are air-dried indoor and set up for the strain gauges instalment in the concrete surface. The strain gauges are installed at the concrete compression fibre. After the installation of the strain gauge, the columns are then painted white and are gridded using a marker to ease the observation of the crack propagation to the incremental lateral loads.

\subsection{Specimens testing}

\subsubsection{Hammer testing}

Hammer testing was intended to verify the distribution of the concrete strength along the specimens' height. The testing point is prepared with a spacing of $40 \mathrm{~mm}$, avoiding the reading on the reinforcing area. The reading is conducted with a reading angle of 0 degrees using a Schmidt hammer apparatus. 


\subsubsection{Concrete compression test and steel tensile test}

The testing of the compressive strength of the cylindrical concrete specimens and tensile strength rebars is done to obtain the actual strength of the designed concrete mix and the reinforcing steel. The test results are then used to update the calculation of the column design. The testing shows that the designed mix of $20 \mathrm{MPa}$ and $30 \mathrm{MPa}$ results in an actual compressive strength of $23.65 \mathrm{MPa}$ and $29.32 \mathrm{MPa}$ respectively. The uniaxial tensile test on the longitudinal bars and the stirrups confirm that the steel with a diameter of $8 \mathrm{~mm}$ yields at 319,74 MPa and fails at $462,79 \mathrm{MPa}$, meanwhile, the $6 \mathrm{~mm}$ steel reaches 258,86 $\mathrm{MPa}$ at yield point and $406,27 \mathrm{MPa}$ at the ultimate stage.

\subsubsection{Lateral loading test}

Both the uniform RC column and GCC are set up for a lateral loading test on a loading frame one at a time. The lateral loading test is equipped with a load cell type CLP-100KNB from Tokyo Sokki Kenkyujo Co., Ltd with a capacity of $100 \mathrm{kN}$, transducers type DDP50A from Tokyo Sokki Kenkyujo Co., Ltd, magnetic bases, an Enerpac RC-1510 hydraulic jack with a capacity of 15 tons, and a TDS-150 data logger from Tokyo Sokki Kenkyujo Co., Ltd with a set up shown in Figure 4.

The RC column is set vertically on the loading frame and is anchored at the bottom using $16 \mathrm{~mm}$ bolts. The hydraulic jack is positioned horizontally and is pointed at the top. A solid steel bar is inserted between the loading head and the concrete surface to allow a good transfer of loads from the jack to the specimens. Two pieces of the transducer are projected on the column's side to record the top and bottom translation during the loading. The transducer positioned at the bottom is aimed to control column stability during testing. An incremental load of $0.2 \mathrm{kN}$ loading step is given using a manual hydraulic pump and is recorded using a load cell.

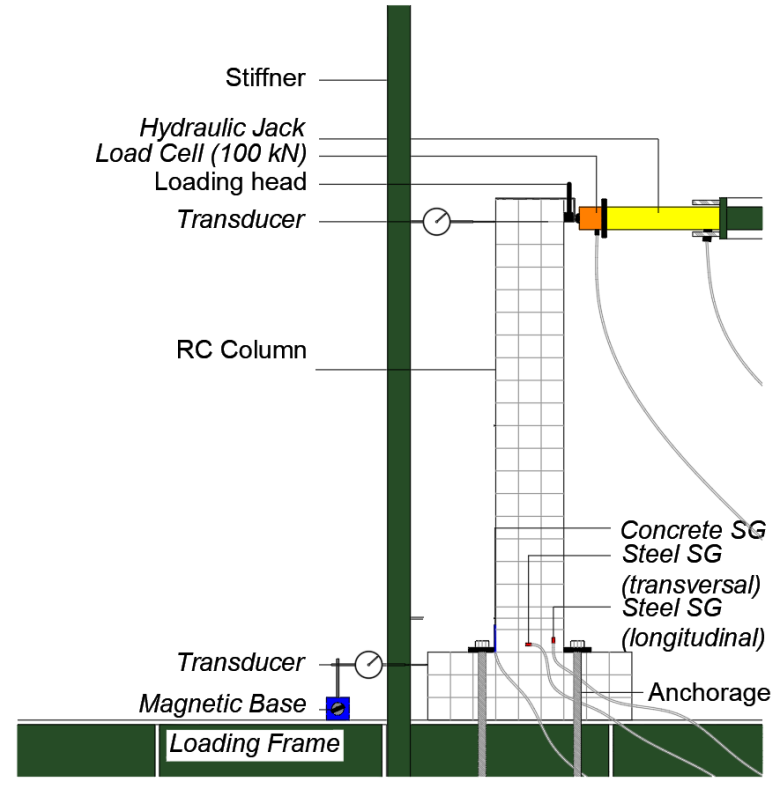

Fig. 4. Column test set up. 


\section{Results and discussion}

\subsection{Hammer test}

The hammer test is conducted along the column's height with an incremental space of 40 $\mathrm{mm}$ while avoiding the reinforcement area. The result shows that the NC creates a compressive strength pattern that increases to the bottom part. Even though the NC column is expected to possess a uniformly distributed concrete strength, the presence of natural segregation makes the coarse aggregates concentrate mostly at the lower section of the element. This phenomenon increases the concrete density and reduces the air void so the reading of the rebound number results in a higher record. The use of the lower concrete strength design also makes the fresh mix prone to the risk of bleeding and segregation and changes the material uniformity. This is in agreement with the research findings of Hidayat [10] and Corinaldesi [11] that emphasize the segregation in deep elements. On the other hand, the reading of the hammer test confirms that the GCC creates a good strength transition in its structure. The graded structure is successfully created as planned where the concrete strength increases by the increment of the column's height. The result of the concrete strength prediction from the hammer test is shown in Figure 5.

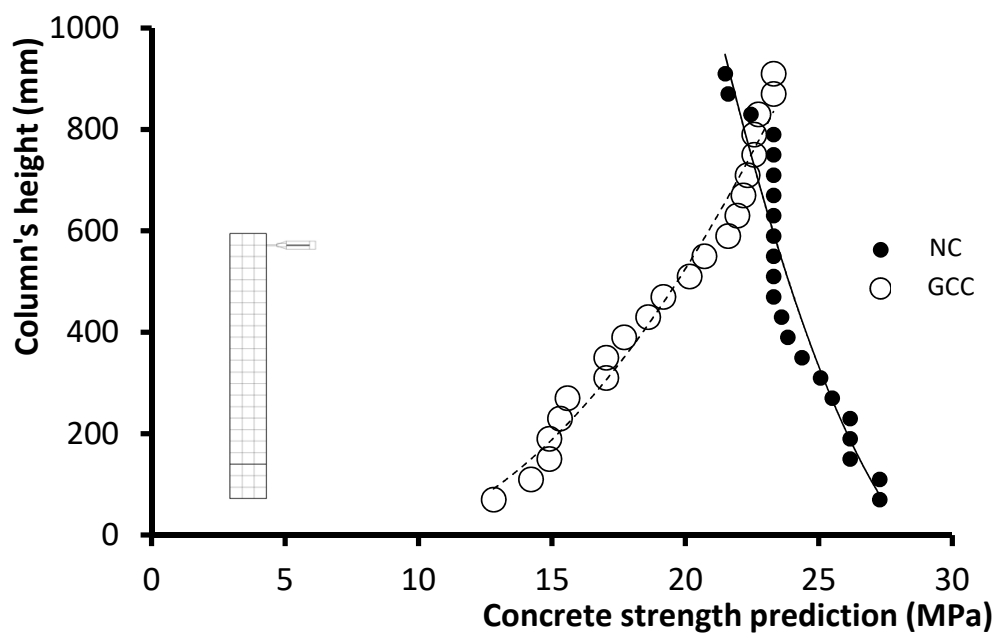

Fig. 5. Distribution of concrete strength on GCC and NC.

\subsection{Lateral loading test}

The reading of the load cell and transducer positioned on the top of the column are plotted to create the graph of lateral loads - translation of the columns. The relationship of lateral loads and translation on the GCC and NC are displayed in Figure 6 below. 


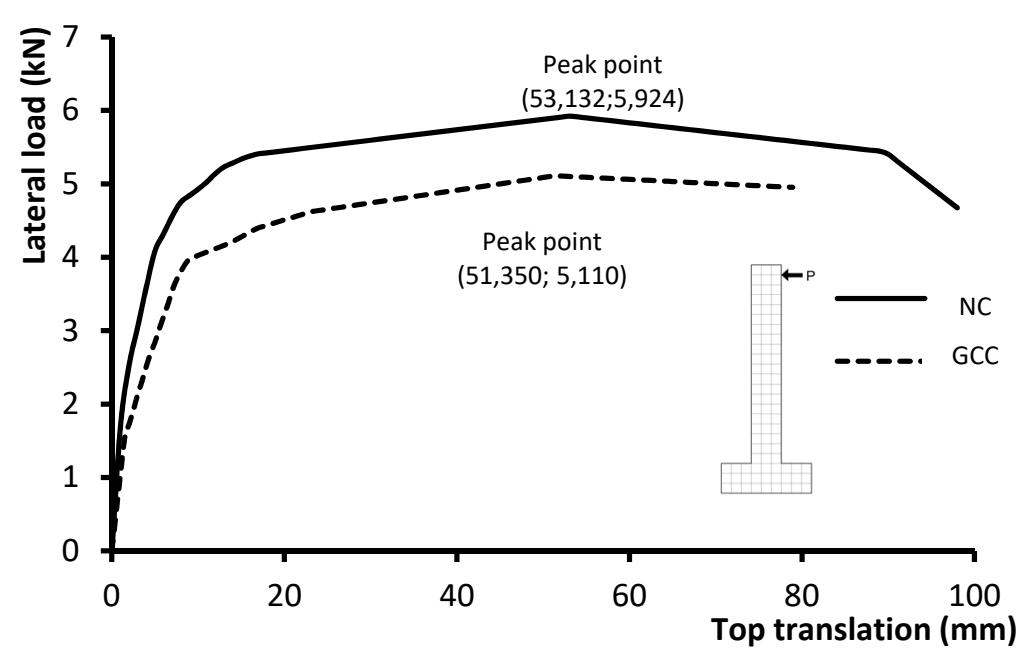

Fig. 6. Lateral load - top translation relation of GCC and NC.

The distinguished curves are observed from the graph. The GCC yields a lower peak load and possesses a slightly lower stiffness than the NC. The GCC reaches its peak load at $5.110 \mathrm{kN}$ which is $13.7 \%$ lower than the NC yield. At the peak level, the GCC sways $51.350 \mathrm{~mm}$ or $3.35 \%$ less than the NC yielding at $53.132 \mathrm{~mm}$. Due to the lateral loads, the shear force and bending moment concentrate at the end support of the column. The lowest concrete strength positioned at the bottom of the GCC will determine the resulting capacity of the column. The lower load resistance causes the column to fail at an early stage of loading and affects the lower resulting stiffness of the element. This agrees with the research conducted by El-Attar [12].

Based on the reading of strain gauges on the concrete surface and the reinforcing bars, the GCC and the NC undergo different failure modes. The GCC exhibits a compression failure while the NC experience a tension failure. On the GCC, the failure is begun by concrete crushing on the compression fibre at $5.790 \mathrm{kN}$ and is followed by the steel yielding at tension fibre after the peak load is reached. On the other hand, the failure of the NC is initiated by the yielding of the tension longitudinal bar at $5.792 \mathrm{kN}$ and continued by the concrete crushing at the ultimate load, $4.627 \mathrm{kN}$, where the column has no stiffness to withstand the load. It is understood that the concrete strength distribution on the column could drastically turn the failure into a different mode and decrease the column capacity.

\section{Conclusion}

From this experimental test, the researchers could conclude that:

- Static segregation on a high element such as a column is unavoidable due to the effect of dimension ratio and the characteristics of the concrete material.

- Concrete strength gradation in a column decreases the capacity of the lateral load by $15.93 \%$ to the normal concrete column and decreases the maximum translation up to $3.47 \%$. 
- Concrete segregation can change the failure mode from tension-controlled failure to compression-controlled failure.

- More brittle behaviour is observed in the segregated column.

Researchers wish to acknowledge PT. Sika Indonesia and PT. BASF Indonesia for providing material support during the research.

\section{References}

1. L. Shen, L. Struble, and D. Lange, ACI Mater. J. 106, 375, (2009)

2. L. Shen, L. Struble, and D. Lange, ACI Mater. J. 106, 367, (2009)

3. K. Kovler and N. Roussel, Cem. Concr. Res. 41, 775, (2011)

4. H. Ay Lie, B.S. Gan, S. As'ad, and M.M.A. Pratama, Int. J. Eng. Technol. Innov. 5, 233, (2015)

5. M. Mirza Abdillah Pratama, H. Ay Lie, B. Sthenly Gan, B. Sri Umniati, P. Risdanareni, and S. Fauziyah, AIP Conf. Proc. 1887, (2017)

6. A.L. Han, B.S. Gan, and M.M.A. Pratama, Int. J. Technol. 7, 732, (2016)

7. B.S. Gan, H. Ay Lie, and M.M.A. Pratama, in Procedia Eng., 885-991, (2015)

8. Sulistyana, Purwanto, V. Widoanindyawati, and M.M.A. Pratama, in Procedia Eng., 465-472, (2014)

9. M.M.A. Pratama. An Experimental Study and Finite Element Approach to the Behavior of Graded Concrete, September 2015, DOI10.13140/RG.2.1.4082.4568, Thesis for: Master of Engineering, Universitas Diponegoro, Indonesia, (2015).

10. A. Hidayat, P. Purwanto, J. Puspowardojo, and F.A. Aziz, in Procedia Eng., 10231029, (2015)

11. V. Corinaldesi, and G. Moriconi, in International RILEM Conference on the Use of Recycled Materials in Buildings and Structures, $600-609$

12. M.M. EL-Attar, H.Z. El-Karmoty, and A.A. EL-Moneim, HBRC J. 12, 284, (2016) 